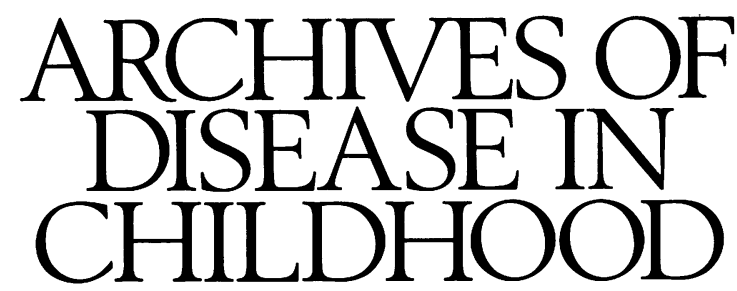

The fournal of the British Paediatric Association

\title{
Annotation
}

\section{Neonatal BCG immunisation}

Since its introduction in 1921 the efficacy of bacille Calmette-Guérin (BCG) has been extensively debated, yet it remains one of the most widely used of all vaccines today. BCG is compulsory in 64 countries and is officially recommended in a further $118 .^{1}$ Schedules differ widely, a testimony to the lack of consensus regarding timing of immunisation. There is growing evidence that neonatal BCG immunisation significantly reduces the risk of clinical tuberculosis.

\section{The controversy}

In 10 randomised controlled trials conducted throughout the world since the 1930 s, the protective efficacy of BCG vaccination (percentage reduction in risk attributable to vaccination) ranged from $0-80 \% .^{2}$ The largest and most widely publicised trial from southern India, which reported no protection, only investigated sputum positive disease and did not include neonates. ${ }^{3}$ Only two out of these 10 trials evaluated neonatal BCG vaccination. Both were performed in North America and vaccine efficacy was estimated to be $75-80 \%{ }^{45}$

An alternative form of assessing the vaccine is the casecontrol study in which identified cases of infection have been matched with up to four controls. Those studies which have specifically addressed neonatal BCG vaccination have reported protection rates greater than $80 \% .^{6}$

Several factors may explain the widely divergent results of the major trials. These include vaccine potency, study design, age at vaccination, regional differences in Mycobacterium tuberculosis strains, nutritional or genetic differences in the trial population, and interaction of vaccines with different mycobacteria which may reduce vaccine efficacy. ${ }^{1}$ The answer defies a simple explanation and it is probable that multiple variables are operational.

Although tuberculin sensitivity is the clinical marker of an immunological response to BCG, a positive tuberculin test does not always imply protection to the disease. ${ }^{8}$ In a Birmingham study, which demonstrated a protective effect of BCG, there were 108 children with tuberculosis of whom 62 had received the vaccine. Of these 36 had postvaccination testing (three months later) and 31 were found to be tuberculin positive. ${ }^{9}$ Approximately $90 \%$ of children have been found to be tuberculin positive four to five years after neonatal BCG. ${ }^{10} 11$

BCG immunisation and tuberculous meningitis

Tuberculosis of the central nervous system continues to be the most devastating form of childhood tuberculosis. Major neurological sequelae follow in up to $70 \%$ of cases, ${ }^{12}$ with reported mortality rates of $20 \% .^{13}$ Several case-control studies have reported vaccine efficacy of $85-100 \%$ against tuberculous meningitis. ${ }^{6714}$ There is evidence that the effect of BCG vaccination is to limit the multiplication and dissemination of the tubercle bacillus. ${ }^{15}$ Immunisation does not prevent the establishment of infection in someone exposed to disease. This may explain the higher protection afforded against tuberculous meningitis and other disseminated forms of tuberculosis.

\section{Neonatal BCG immunisation and immunodeficiency} syndromes including HIV infection

Several cases have been reported of disseminated BCG in adults with symptomatic HIV infection at the time of immunisation. ${ }^{16}$ Disseminated disease has been described after BCG in an infant born to a mother with AIDS related complex. ${ }^{17}$ In a prospective study in the Congo the frequency of BCG lymphadenitis in a group of HIV infected children was not significantly different from a group of uninfected children after neonatal BCG. ${ }^{18}$ Disseminated forms of disease were not seen. It is not known whether BCG is protective in children who are HIV positive. The World Health Organisation has recommended that neonatal BCG should be given in areas where there is a high prevalence of both tuberculosis and HIV infection. ${ }^{19}$ But BCG is not recommended for HIV infected children (asymptomatic or symptomatic) in areas of low tuberculosis endemicity. As yet there is no indication to check HIV status in those infants from the high risk groups before administering BCG. The risk of disseminated BCG infection among babies with severe congenital immunodeficięncy is unknown. Disseminated BCG was seen in 1/300 000 newborn infants given BCG routinely in Chile; those infants affected were thought to have congenital immunodeficiency. ${ }^{20}$ In a British population the incidence of severe combined immunodeficiency is thought to be $1 / 60000$.

\section{Complications of neonatal BCG}

Ulceration at the site of inoculation and osteitis are said to be more common in the newborn. An incidence of BCG osteitis of 29/100 000 prompted Sweden to abandon their neonatal BCG programme in 197.5. ${ }^{21}$ This particularly high incidence may have been related to the strain of vaccine used. 


\section{Tuberculosis in the UK}

There were 5432 cases of tuberculosis notified to the Office of Population and Census and Surveys in 1989. ${ }^{22}$ Ten per cent of cases occurred in children. Tuberculous meningitis accounted for less than $1 \%$ of the total cases but $30 \%$ of these occurred in children. In a survey in 1983 of all notifications of tuberculosis in children the highest rates occurred in children of Indian subcontinent ethnic origin: $32 / 100000$ for the Indian and 52/100 000 for the Pakistani and Bangladeshi groups. ${ }^{23}$ The rate for white children was $2 \cdot 4 / 100000$. Nevertheless white children accounted for $48 \%$ of the total number of cases. Altogether $75 \%$ of cases of tuberculous meningitis occurred in children under 5 years and were thus in the age group that could have been protected by neonatal BCG vaccination.

\section{Current practice in the UK}

The Department of Health ${ }^{24}$ and the British Paediatric Association ${ }^{25}$ recommend a selective policy of neonatal BCG vaccination. They advise that the following groups should receive the vaccine at birth: (i) babies of Asian and other immigrant families with high tuberculosis rates, (ii) infants who reside in or travel to areas where the risk of contracting tuberculosis is thought to be high, (iii) those in contact with active respiratory tuberculosis, and (iv) infants with a family history of tuberculosis in the preceding five years. In a recent yet unpublished survey carried out by the Public Health Laboratory Service (PHLS), Communicable Disease Surveillance Centre, 31 out of 174 district health authorities in England and Wales did not offer BCG immunistaion to the newborn (John Watson, PHLS, personal communication). In addition to the high risk groups referred to above there may be areas where other children are at risk. The rate of tuberculosis in white inner city Leeds children at $5 \cdot 5 / 100000$ was similar to that of children whose parents originated from the Indian subcontinent $(6 \cdot 2 / 100000) .{ }^{26}$

\section{Conclusion}

Neonatal BCG offers almost complete protection to meningitis and other disseminated forms of tuberculosis in childhood. It is less effective against respiratory disease protecting some $65 \%$ of children exposed to infection. 67 Although the incidence of tuberculosis in the UK declined in the early 1980s there has been a recent increase, possibly related to the HIV epidemic, but increases in notifications have been seen in districts with high proportions of residents of Indian subcontinent ethnic origin. ${ }^{27}$ Paedia- tricians should ensure that children at high risk of tuberculosis are protected from this disease.

Children's Centre,

Royal United Hospital,

ANTONIA CLARKE

Bath BAI 3NG

PETER RUDD

1 World Health Organisation. BCG vaccination policies. Report of a WHO study group. WHO Tech Rep Ser No 652. Geneva: WHO, 1980

2 Fine PEM. The BCG story: lessons from the past and implications for the future. Rev Infect Dis 1989;11(suppl 2):353-9.

3 Trial of BCG vaccines in south India for tuberculosis prevention: first report-tuberculosis prevention trial. Bull World Health Organ 1979;57: 819-27.

4 Ferguson RG, Simes AB. BCG vaccination of Indian infants in Saskatchewan Tubercle 1949;30:5-11.

5 Rosenthal SR, Loewinsohn E, Graham ML, Liveright D, Thorne MG, Johnson V. BCG vaccination against tuberculosis in Chicago. A twenty year study statistically analysed. Pediatrics 1961;28:622-41.

6 Miceli I, Kantor I, Colaiacovo D, et al. Evaluation of effectiveness of BCG vaccination using the case-control method in Buenos Aires, Argentina. Int $\mathcal{F}$ Epidemiol 1988;17:629-34.

7 Sirinavin S, Chotpitayasunondh T, Suwanjutha S, Sunakorn P, Chantarojanasiri T. Protective efficacy of neonatal Bacillus Calmette-Guerin vacjanasiri T. Protective efficacy of neonatal Bacillus Calmette-Gue
cination against tuberculosis. Pediatr Infect Dis $\mathcal{7}$ 1991;10:359-65.

8 Hart PD'A, Sutherland I, Thomas J. The immunity conferred by effective BCG and vole bacillus vaccines, in relation to individual variations induced tuberculin sensitivity and to technical variations in the vaccines. Tubercle 1967;48:201-10.

9 Packe GE, Innes JA. Protective effect of BCG vaccination in infant Asians: a case-controlled study. Arch Dis Child 1988;63:277-81.

10 Ormerod LP, Garnett JM. Tuberculin skin reactivity four years after neonatal BCG vaccination. Arch Dis Child 1992;67:530-1.

11 Crawshaw PAG, Thompson AH. Heaf test results after neonatal BCG. Arch Dis Child 1988;63:1490-1.

12 Waecker NJ, Connor JD. Central nervous system tuberculosis in children: review of 30 cases. Pediatr Infect Dis 7 1990;9:539-43.

13 Idriss ZH, Sinno AA, Kronfol NM. Tuberculous meningitis in childhood: 43 cases. Am $\mathcal{F}$ Dis Child 1976;130:346-7.

14 Filho VW, de Castilho EA, Rodriques LC, Huttly SRA. Effectiveness of BCG vaccination against tuberculous meningitis: a case-control study in Sao vaccination against tuberculous meningitis: a case-con
Paulo, Brazil. Bull World Health Organ 1990;68:69-74.

15 Sutherland I, Lindgren I. The protective effect of BCG vaccination as indicated by autopsy studies. Tubercle 1979;60:225-31.

16 Quinn TC. Interactions of the human immunodeficiency virus and tuberculosis and implications for BCG vaccination. Rev Infect Dis 1989;11(suppl 2):379-83

17 Ninane J, Grymonprez A, Burtonboy G, Francois A, Cornu G. Disseminated BCG in HIV infection. Arch Dis Child 1988;63:1268-9.

18 Lallemant Le Coeur S, Lallemant M, Cheynier D, Nzingoula S, Deucker I, Larouze B. Bacillus Calmette-Guerin immunisation in infants born to HIV1-seropositive mothers. AIDS 1991;5:195-9.

19 La Force FM. Immunisation of children infected with human immunodeficiency virus. Expanded programme on immunisation (HIV). Geneva: World Health Organisation. (WHO/EPI/86/6.)

20 Gonzalez B, Morena S, Burdach, R, et al. Clinical presentations of Bacillus Calmette-Guerin infections in patients with immunodeficiency syndromes. Pediatr Infect Dis f 1989;8:201-6

21 Romanus V. Childhood tuberculosis in Sweden. An epidemiological study made six years after the cessation of general BCG vaccination of the made six years after the cessation
newborn. Tubercle 1983;64:101-10.

22 Office of Population Censuses and Surveys. Communicable disease statistics, England and Wales. Series MB2. London: HMSO, 1990.

23 Medical Research Council Tuberculosis and Chest Diseases Unit. Tuberculosis in children; a national survey of notifications in England and Wales in 1983. in children; a national survey of
Arch Dis Child 1988;63:266-76.

24 Department of Health, Welsh Office, Scottish Home and Health Department. Immunisation against infectious disease. London: HMSO, 1990.

25 Rudd P, Nicoll A. Manual on infections and immunizations in children. 2nd Ed. Oxford: Oxford Medical Publications for the British Paediatric Association, 1991 .

26 Cundall DB, Pearson SB. Inner city tuberculosis and immunisation policy Arch Dis Child 1988;63:964-6.

27 Watson JM. Tuberculosis in perspective. Communicable Disease Report 1991;1:R129-31. 